\title{
Chapter 20 \\ How Analysis of Mortality by Cause of Death Is Currently Influencing UK Forecasts
}

\author{
Richard Willets
}

The purpose of this paper is to examine the potential benefits of cause of death analysis in the context of projecting future mortality rates in the UK.

In the first section of the paper the main features of recent mortality trends in the UK are briefly described. In the second methods currently used to project mortality in the UK are outlined. Current issues and topics for research are also discussed. In section three potential causes of the "UK cohort effect" are listed and the role of cigarette smoking, in particular, is discussed. A model of mortality which includes a year of birth component is discussed in section four. It is argued that models such as this can be used to analyse mortality from different causes and this analysis can have important benefits. Conclusions and implications are given in section five.

Throughout the paper most emphasis is placed on understanding and modelling mortality trends for older adults. This part of the age range is currently the focus of most research in the UK and has the greatest financial significance in terms of its impact on pension schemes and public finances.

\subsection{Mortality Improvement in the UK}

In common with many developed countries round the world, the UK has recently experienced substantial reductions in mortality rates. The pace of improvement, especially at older ages, has accelerated strongly as the figures in Table 20.1 demonstrate.

Table 20.1 shows that broadly the same fall (circa 20\%) in the rate of mortality for males aged 65-74 has occurred in successive periods of 68, 17, 10 and then 6 years.

\footnotetext{
R. Willets $(\bowtie)$

Willets Consulting Limited, Minneapolis, MN, USA

(C) The Author(s) 2019

T. Bengtsson, N. Keilman (eds.), Old and New Perspectives on Mortality

Forecasting, Demographic Research Monographs,

https://doi.org/10.1007/978-3-030-05075-7_20
} 
Table 20.1 Reduction in the mortality rate for males aged $65-74$ in the England \& Wales population since 1901

\begin{tabular}{ll}
\hline Time period & Reduction in the mortality rate for males aged $65-74$ \\
\hline $1901-1969$ (68 years) & $19.4 \%$ \\
$1969-1986$ (17 years) & $21.6 \%$ \\
$1986-1996$ (10 years) & $19.4 \%$ \\
$1996-2002$ (6 years) & $21.1 \%$
\end{tabular}

Source: The Office for National Statistics

The pace of change at the beginning of the twenty-first century has therefore been more than ten times as rapid as that seen in the first seven decades of the twentieth century.

This simple example illustrates the extent to which the pace of change in mortality rates at older ages has improved over time. More generally, we have seen a trend towards faster improvements at older ages, but less rapid change at younger ages. This feature of mortality change has applied to many developed countries and is sometimes referred to as the "aging of mortality improvement" (Wilmoth 1997).

Figure 20.1a, b illustrate this trend of more rapid improvement at increasingly advanced ages by comparing average annual rates of mortality improvement ${ }^{1}$ over the past four decades with rates for the previous 50 years.

In terms of individual causes of death, the single most important driver of these accelerated improvements has been the substantial reduction in heart disease mortality seen in recent decades. This is illustrated by Fig. 20.2a, which shows the crude rate of heart disease mortality for men aged 65-74.

Figure 20.2a shows that the death rate from heart disease for men aged 65-74 has fallen by almost $60 \%$ since 1985 . The reduction is equivalent to an annual rate of improvement of $4.8 \%$ p.a.

The major contributor to the decline in heart disease mortality is believed to be reduced cigarette smoking prevalence (Kelly and Capewell 2004). However, reduction in population blood pressure and cholesterol levels and improvements in treatment have also played a significant role. These positive trends have comfortably outweighed the impact of adverse trends in obesity, diabetes and lack of physical activity, which together contributed approximately 8000 extra deaths in England \& Wales between 1981 and 2000 (Unal et al. 2004).

There have also been substantial reductions in other leading causes of death, such as stroke and cancer, at these ages, as illustrated by Figs. $20.2 \mathrm{~b}$ and $20.2 \mathrm{c}$.

However, the major contributor to the recent rapid improvement in mortality at older ages has been heart disease. Willets et al. (2004) showed that over half of the recent mortality improvement for men in their 60s in England \& Wales was due to heart disease alone. The figures in Table 20.2 also show that most of the remainder of the improvement was due to reductions in stroke and cancer mortality.

\footnotetext{
${ }^{1}$ Throughout this paper the term "mortality improvement rate" is taken to mean the rate of change in the mortality rate at a given age from year to the next, i.e. $1-\mathrm{m}(\mathrm{x}, \mathrm{t}) / \mathrm{m}(\mathrm{x}, \mathrm{t}-1)$, where $\mathrm{m}(\mathrm{x}, \mathrm{t})$ is the central mortality rate for age $\mathrm{x}$ and time $\mathrm{t}$.
} 

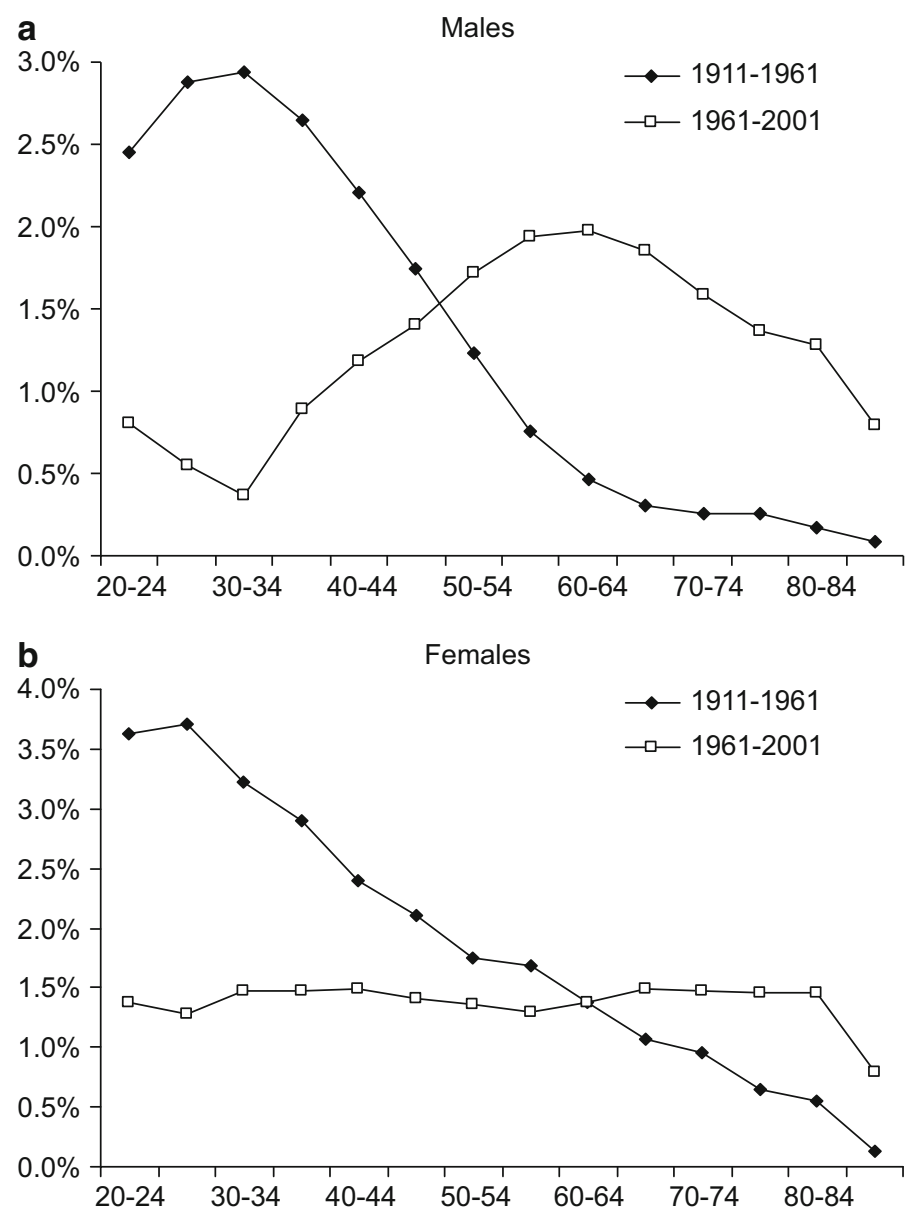

Source: The Office for National Statistics

Fig. 20.1 Average annual mortality improvement rates, England \& Wales population, 1911-2001. (a) males, (b) females. (Source: The Office for National Statistics)

It is also worth noting that at younger ages, such as the 30-39 age group, improvements in mortality due to heart disease, stroke and cancer have been more than offset by adverse trends in other causes, notably those linked to drug and alcohol abuse.

In addition to this trend of accelerating improvements at older ages, UK patterns of mortality change have also been influenced by the feature sometimes referred to as the "UK cohort effect".

Figure 20.3a, b show how the pace of improvement (the average annual reduction in mortality rates) has varied by year of birth in successive 10 -year periods. Three features are evident in both figures: 


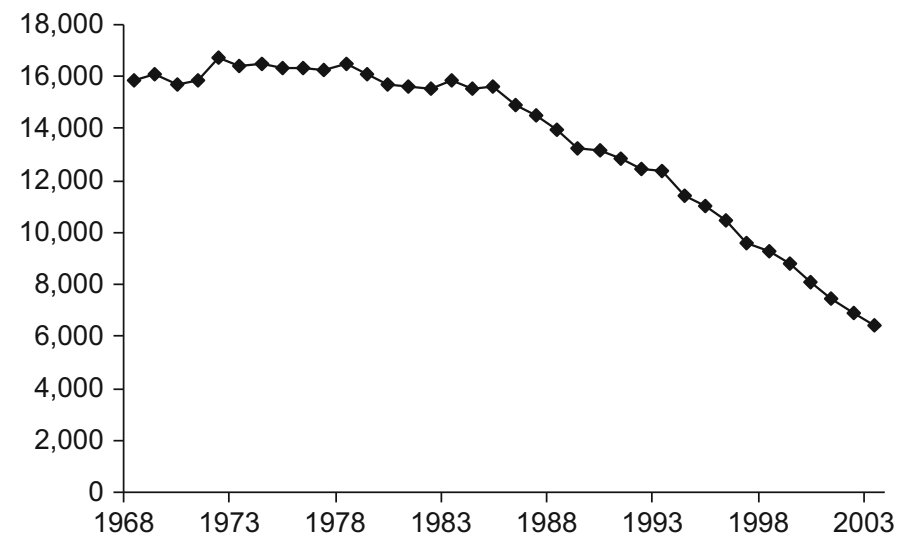

Fig. 20.2a Heart disease deaths per $1,000,000$, ages $65-74$, England \& Wales population, 1968-2003, males. (Source: The Office for National Statistics)

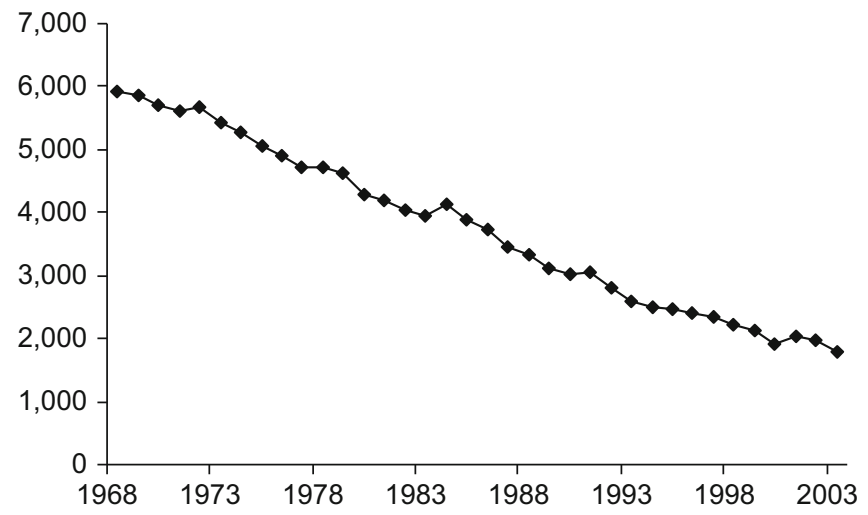

Fig. 20.2b Stroke deaths per 1,000,000, ages 65-74, England \& Wales population, 1968-2003, males

- The pace of improvement has been consistently higher for people born in the period 1925-1945 than for people born either side of this generation (this being the so-called "UK cohort effect"). In particular more rapid improvement has been a feature of mortality change for those born in the period 1925-1935, with a secondary peak around 1945 .

- Many of the peaks and troughs in the rates of improvement are replicated over time, showing the enduring significance of year of birth in determining the pace of change at different ages.

- The pace of improvement within birth cohorts has increased over time. In other words, the pace of improvement has been accelerating in recent decades, after allowing for the impact of the cohort effect. 


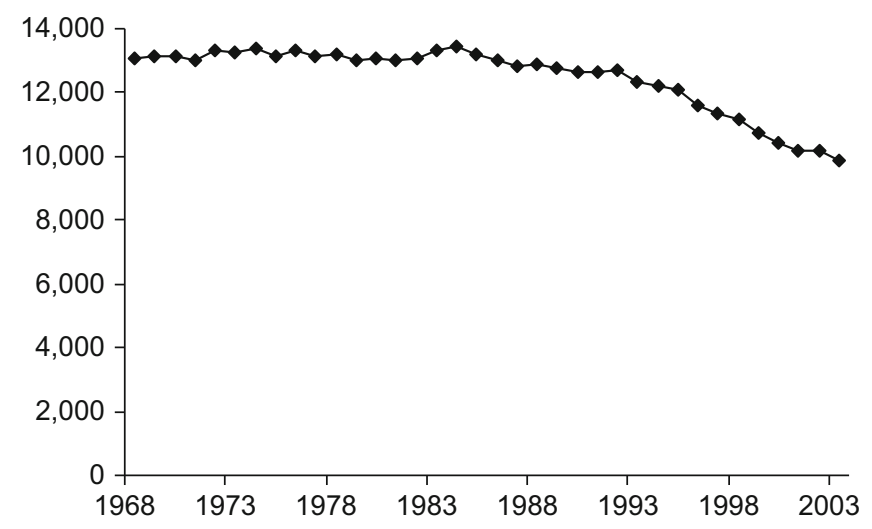

Fig. 20.2c Cancer deaths per 1,000,000, ages 65-74, England \& Wales population, 1968-2003, males. (Source: The Office for National Statistics)

Table 20.2 Breakdown of contributions to the overall rate of mortality improvement over the period 1989-2001, by cause, England \& Wales population, males

\begin{tabular}{lcc}
\hline Cause & Ages 30-39 & Ages 60-69 \\
\hline Heart disease & $+0.4 \%$ & $+1.8 \%$ \\
Stroke & $+0.3 \%$ & $+0.3 \%$ \\
Cancer & $+0.1 \%$ & $+0.9 \%$ \\
AIDS & $+0.3 \%$ & $0.0 \%$ \\
Drugs/alcohol/liver disease & $-0.8 \%$ & $0.0 \%$ \\
Violent/accidental & $-0.3 \%$ & $+0.3 \%$ \\
All others & $0.0 \%$ & $+0.4 \%$ \\
\hline Aggregate & $-0.1 \%$ & $+3.4 \%$ \\
\hline
\end{tabular}

It is also worth noting that a similar effect can be seen in other developed countries. Data from the Human Mortality Database maintained by the University of California, Berkeley (USA) and Max Planck Institute for Demographic Research (Germany) was analysed for $17^{2}$ developed countries (all those included on the database excluding those in Eastern Europe). For each of the 17 countries data from 1950 to 2003 for ages 40 to 89 (subject to the years available in each case) were used to calculate average rates of mortality improvement by year of birth.

The results are illustrated by Fig. 20.4. It is notable that the pace of improvement has been significantly more rapid for males born in or around 1935-1940 than generations born before or after this period. ${ }^{3}$

\footnotetext{
${ }^{2}$ Austria, Belgium, Canada, Denmark, England \& Wales, Finland, France, Italy, Japan, Netherlands, New Zealand, Norway, Spain, Sweden, Switzerland, USA and West Germany.

${ }^{3}$ It is also worth noting that the trough in the pace of improvement for the "1920-born" generation is actually far lower than Figure 20.4 suggests. Without the impact of smoothing, the figure for this year is minus $7.8 \%$ p.a. This feature is likely to have been caused by the impact of the 1919 influenza pandemic.
} 


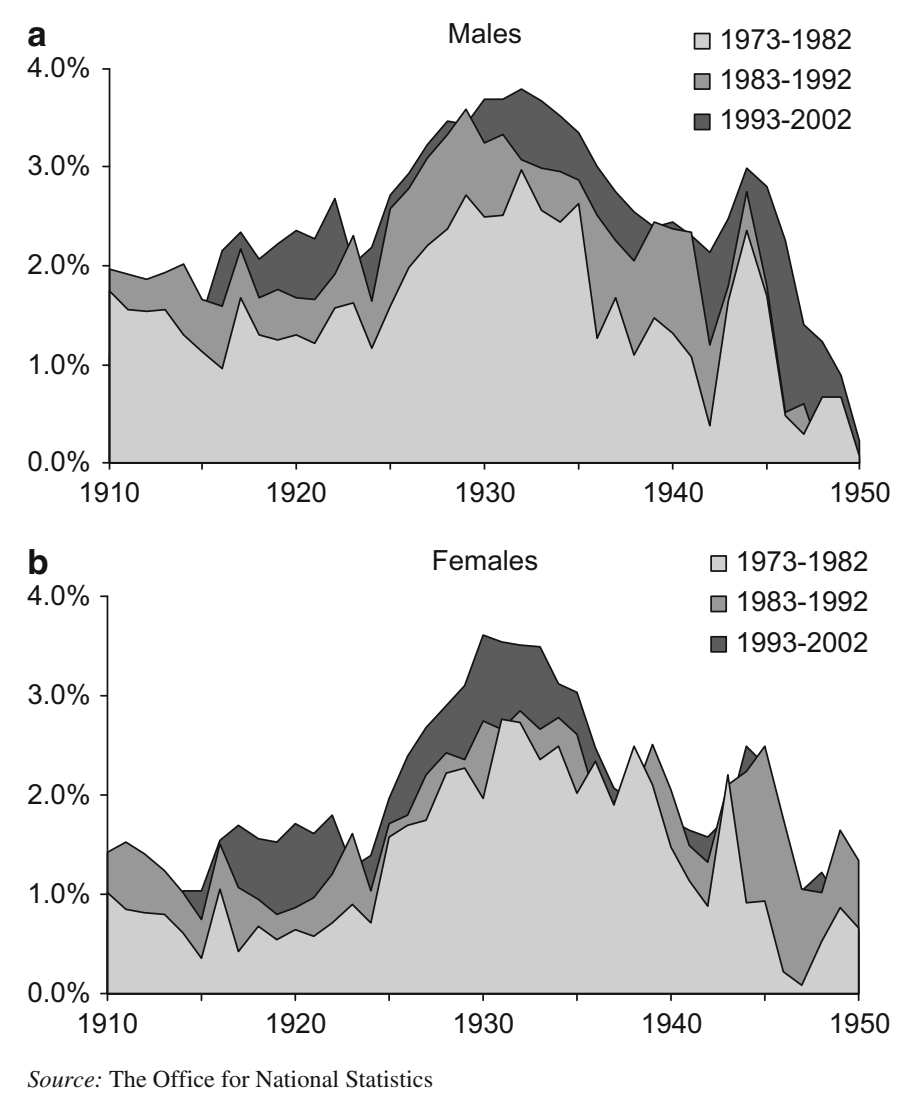

Fig. 20.3 Rate of mortality improvement by year of birth and 10-year period, England \& Wales, smoothed using 7-year rolling averages. (a) males, (b) females. (Source: The Office for National Statistics)

\subsection{Current Methodologies and Research in the UK}

Mortality projections for the UK population are currently produced by the Government Actuary's Department (GAD). The projections assume that "current" rates of mortality improvement - based on the most-recent trends in aggregate mortality will converge with target rates over a 25 -year time-frame.

The latest projection, the so-called "2002-based" projection (GAD 2003), assumed target rates of improvement of $1.0 \%$ p.a. for both males and females.

The rates of improvement are projected on a cohort basis for generations born prior to 1947.

A number of variant projections are also made using alternative improvement scenarios.

Projections of future mortality for pensioners and annuitants in the UK are produced by the Continuous Mortality Investigation (CMI), a research group of 


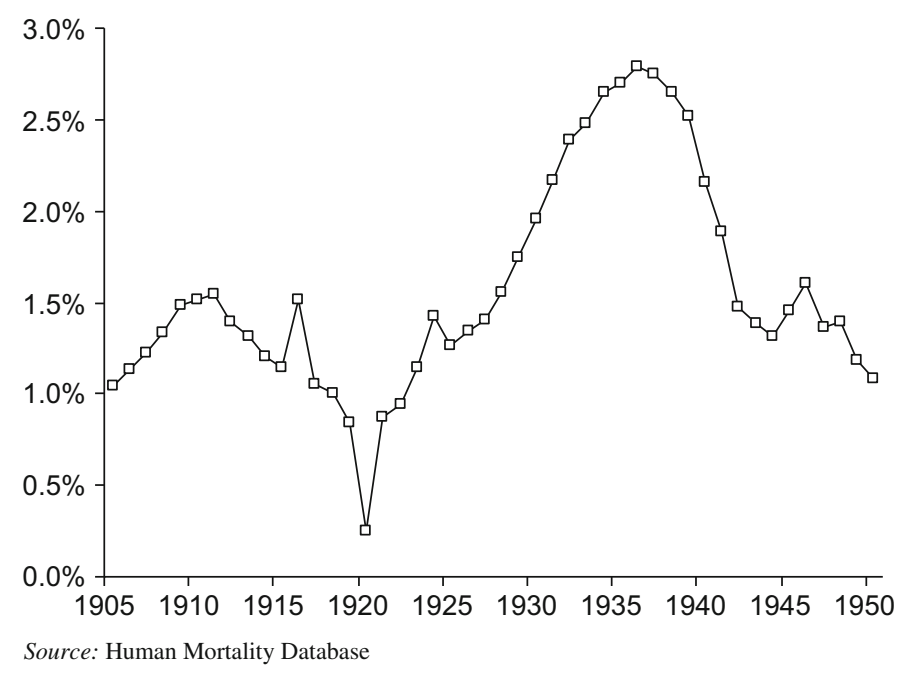

Fig. 20.4 Average annual rate of mortality improvement by year of birth for 17 developed countries, males, ages 40-89, data from 1950 to 2003, figures smoothed using rolling averages. (Source: Human Mortality Database)

the UK Actuarial Profession. The last official projection, published in conjunction with the "92 series" of mortality tables for pensioners and annuitants, is based on assumed rates of future improvement in historic trends by age group (CMI 1999). Rates of improvement in the so-called "CMIR17" basis were assumed to diminish over time, consistent with the idea of ultimate (or minimum) rates of mortality.

In 2002 interim "cohort" projections were published by the CMI (CMI 2002) which combined the rates of change in the CMIR17 basis with blocks of rapid improvement consistent with the projection of the UK cohort effect into advanced ages. Three variant projections were produced which differed in the extent to which the cohort effect was assumed to be projected forwards into the future.

Both the GAD and CMI projection methodologies project aggregate rates of mortality, rather than using a cause-of-death methodology.

Cause-of-death modelling has not, and is not, generally favoured as an approach for projecting future mortality rates in the UK. The 1976-based GAD projection of UK population mortality did model future improvements for 10 distinct groups of causes of death. However, this methodology was not adopted for future projections and a major review of the projection methodology for the UK population (GAD 2001) concluded that: "projections of mortality should not be carried out by cause of death".

A similar review paper published by the CMI (CMI 2004) sought feedback from the UK Actuarial Profession on the methodology to be adopted for future mortality projections. One question it asked was whether projections should be carried out on an aggregate or a cause-of-death basis. The response was overwhelmingly in favour of an aggregate methodology. 
Arguments against cause-of-death projections included:

- interactions between different causes are difficult to model, especially at older ages;

- medical/research effort will shift as the relative importance of different causes changes over time;

- there are problems with classifying the true cause of death in the very old; and

- changing methods of cause classification over time can distort trends.

Much of the research on future mortality improvement currently being carried out in the UK is being driven by regulatory change in the UK insurance industry which favours a stochastic approach to modelling risk.

Major topics of research include all forms of stochastic mortality modelling, such as Lee-Carter and variants, and advanced methods of smoothing mortality surfaces such as p-splines (CMI 2005).

However, two big questions at the time of this writing - at least for the UK insurance and pensions industries - are:

- whether the UK cohort effect will be projected forwards into the future as the 1925-45 generation ages; and,

- whether the pace of improvement in mortality rates for older ages will continue to accelerate.

For instance, a Guidance Note recently published by the UK Actuarial Profession (2004) states that in determining the capital requirements of an insurance company:-

the ICA [Individual Capital Assessment] should consider firstly, with justification, how any historically observed trends (including cohort effects) might continue, or might continue to accelerate or decelerate.

It is difficult to see how such a justification could be obtained without a consideration of the underlying causes of mortality trends, such as the cohort effect.

\subsection{Understanding the "UK Cohort Effect"}

A number of possible causes for the UK cohort effect have been discussed. These include:

- patterns of cigarette consumption;

- the adverse impact of World War II;

- patterns in birth rates;

- the development of the UK Welfare State after World War II;

- the impact of diet in early life/maternal malnutrition; and

- early life exposure to infectious disease/lifetime levels of inflammation. 
These possible causes are discussed in more detail in Willets (2004). However, to illustrate the value of considering mortality trends for different causes of death, the impact of cigarette smoking will be analysed in more detail here.

Cohort effects in lung cancer mortality rates have been well-documented in recent decades (see, for example, Caselli 1996). Indeed, in women especially, the trends in lung cancer mortality in the UK have been described as providing "an almost perfect example of a cohort effect" (Office for National Statistics 1997).

Figure 20.5 shows rates of lung cancer mortality for females in England \& Wales by year of birth. It can clearly be seen that the rate of lung cancer deaths at each age group has peaked for those women born in or around 1925.

A similar pattern can be seen for males in England \& Wales, with the peak rates of lung cancer mortality occurring for men born in or around 1905.

This data closely matches the pattern shown in figures for lifetime consumption of cigarette tar by year of birth (Lee et al. 1990). There is, therefore, strong evidence that trends in lung cancer mortality by year of birth are correlated with trends in cigarette consumption by year of birth. As a result it is a relatively straightforward task to project future rates of lung cancer mortality for mature generations of UK lives.

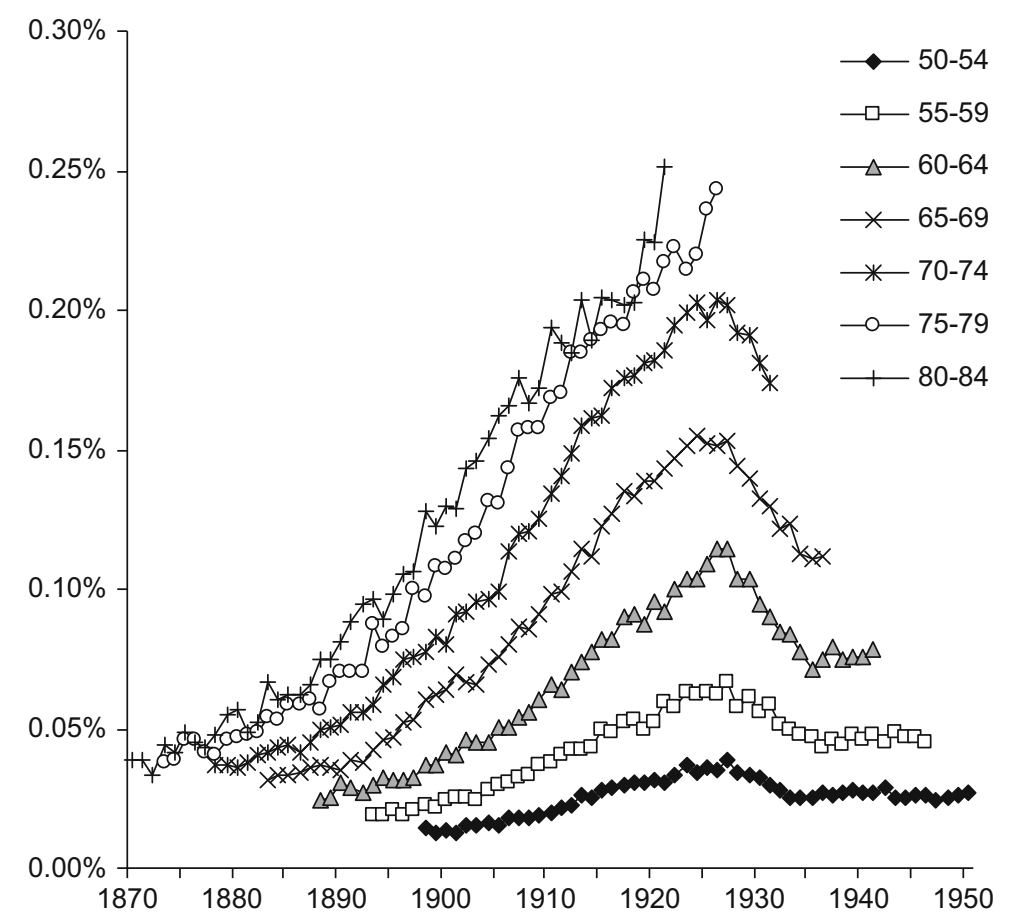

Source: The Office for National Statistics

Fig. 20.5 Rate of lung cancer mortality for females in England \& Wales by year of birth, using data from 1950 to 2003. (Source: The Office for National Statistics) 
As a result of this clear link between lifetime smoking behaviour and mortality from one of the major smoking-related causes of death, it is sometimes argued that the UK cohort effect is unlikely to be projected forwards far into the future.

This argument is based on the suggestion that the UK cohort effect has been largely caused by past patterns in smoking, but that cigarette smoking prevalence has now stabilised in the UK (Office for National Statistics 2004). Furthermore it is argued that smoking-related causes of death (such as lung cancer) are less significant in relative terms at older ages.

In order to explore whether this theory is supported by experience, it is useful to consider historic trends in different causes of death.

\subsection{Modelling Mortality by Cause of Death}

Tables 20.3a, 20.3b, and 20.3c illustrate the pattern of mortality improvement in three major causes of death for females in England \& Wales, namely lung cancer, heart disease and breast cancer. In each case the average annual rate of improvement has been derived for successive periods of 10 years using log linear regression on cause-specific mortality rates.

Table 20.3a clearly shows that the rate of improvement in lung cancer mortality has been particularly rapid for a group of females born in the same period, who are ten years older in each successive 10-year period. The shaded figures relate chiefly to women born in or around 1930. It is notable that the pace of improvement for this cohort has remained relatively constant over time and also that the pace of improvement for adjacent age groups has been far lower.

The equivalent figures for heart disease mortality are given in Table 20.3b.

The pattern of improvement is somewhat different for heart disease. It is evident that the pace of improvement has accelerated over time for all birth cohorts, but that the most rapid pace of change has applied, consistently, to a much wider range of birth years than was the case for lung cancer.

In the case of breast cancer the pace of improvement has also accelerated over time, but was generally greatest for those aged under 50 in 1973-1983, those aged under 60 in 1983-1993 and those aged under 70 in 1993-2003.

Tables 20.3a, 20.3b, and 20.3c only give an approximate indication of cohort effects, by considering age-related improvements in successive periods of time. A more formal analysis can be achieved by modelling mortality rates using an approach in which year of birth parameters are included.

Such a model was constructed using a database of England \& Wales population experience for the period 1968-2003. This period covers the years when deaths were classified using ICD8, ICD9 and ICD10; three versions of the International Classification of Diseases.

Raw deaths data for years from 1968 to 2000 were taken from the 20th Century Mortality database produced by the Office of National Statistics (ONS). More recent data relating to the period 2001-2003 were taken from the twenty-first Century Mortality database (ONS). 
Table 20.3a Average annual rate of lung cancer mortality improvement in successive 10-year periods, England \& Wales population, females

\begin{tabular}{llll}
\hline Age group & $\mathbf{1 9 7 3 - 1 9 8 3}$ & $\mathbf{1 9 8 3 - 1 9 9 3}$ & $\mathbf{1 9 9 3 - 2 0 0 3}$ \\
\hline & & & \\
$40-44$ & $+1.5 \%$ & $-1.9 \%$ & $+4.2 \%$ \\
$45-49$ & $+\mathbf{3 . 7} \%$ & $+0.3 \%$ & $+0.4 \%$ \\
$50-54$ & $+0.4 \%$ & $+0.2 \%$ & $+0.5 \%$ \\
$55-59$ & $-2.7 \%$ & $+\mathbf{3 . 8} \%$ & $-0.5 \%$ \\
$60-64$ & $-3.7 \%$ & $+0.3 \%$ & $+1.3 \%$ \\
$65-69$ & $-4.7 \%$ & $-1.9 \%$ & $+\mathbf{3 . 5} \%$ \\
$70-74$ & $-4.8 \%$ & $-2.6 \%$ & $+0.7 \%$ \\
$75-79$ & $-4.5 \%$ & $-3.1 \%$ & $-2.0 \%$ \\
$80-84$ & $-4.3 \%$ & $-3.5 \%$ & $-2.4 \%$ \\
\hline
\end{tabular}

Source: The Office for National Statistics

Table 20.3b Average annual rate of heart disease mortality improvement in successive 10-year periods, England \& Wales population, females

\begin{tabular}{llll}
\hline Age group & $\mathbf{1 9 7 3 - 1 9 8 3}$ & $\mathbf{1 9 8 3 - 1 9 9 3}$ & $\mathbf{1 9 9 3 - 2 0 0 3}$ \\
\hline & & & \\
$45-49$ & $\mathbf{+ 3 . 6 \%}$ & $\mathbf{+ 5 . 4 \%}$ & $+1.4 \%$ \\
$50-54$ & $+0.6 \%$ & $+\mathbf{5 . 3} \%$ & $+5.0 \%$ \\
$55-59$ & $-0.1 \%$ & $+\mathbf{4 . 8} \%$ & $+\mathbf{6 . 6 \%}$ \\
$60-64$ & $+0.4 \%$ & $+3.2 \%$ & $+\mathbf{7 . 1} \%$ \\
$65-69$ & $+0.7 \%$ & $+2.2 \%$ & $+7.2 \%$ \\
$70-74$ & $+1.1 \%$ & $+2.1 \%$ & $+6.3 \%$ \\
$75-79$ & $+1.2 \%$ & $+1.6 \%$ & $+5.2 \%$ \\
$80-84$ & $+1.5 \%$ & $+1.0 \%$ & $+4.7 \%$ \\
\hline
\end{tabular}

Source: The Office for National Statistics

Mid-year population estimates were also taken from the most up-to-date ONS publications which incorporate the most recent revisions resulting from the 2001 Census results (October 2004).

For each calendar year (1968-2003) death numbers, split by 5-year age groups (up to 80-84) by gender and cause of death, were divided by the equivalent mid-year population estimates. Hence, central mortality rates for 5-year age bands were derived. 
Table 20.3c Average annual rate of breast cancer mortality improvement in successive 10-year periods, England \& Wales population, females

\begin{tabular}{llll}
\hline Age group & $\mathbf{1 9 7 3 - 1 9 8 3}$ & $\mathbf{1 9 8 3 - 1 9 9 3}$ & $\mathbf{1 9 9 3 - 2 0 0 3}$ \\
\hline $45-49$ & $\mathbf{+ 0 . 5} \%$ & $\mathbf{+ 1 . 6 \%}$ & $+\mathbf{3 . 9 \%}$ \\
$50-54$ & $-0.6 \%$ & $+\mathbf{1 . 6} \%$ & $+\mathbf{3 . 5 \%}$ \\
$55-59$ & $-1.1 \%$ & $\mathbf{+ 1 . 7} \%$ & $+\mathbf{2 . 8 \%}$ \\
$60-64$ & $-0.7 \%$ & $+0.6 \%$ & $+\mathbf{2 . 9 \%}$ \\
$65-69$ & $-0.5 \%$ & $+0.2 \%$ & $+\mathbf{3 . 2 \%}$ \\
$70-74$ & $-1.1 \%$ & $+0.3 \%$ & $+2.6 \%$ \\
$75-79$ & $-0.6 \%$ & $-0.5 \%$ & $+1.3 \%$ \\
$80-84$ & $-1.0 \%$ & $-1.1 \%$ & $+1.9 \%$ \\
\hline
\end{tabular}

Source: The Office for National Statistics

Using these central mortality rates for each age group (x) and calendar year ( $\mathrm{t})$, mortality improvement rates were calculated for age groups between 40-44 and 80-84 inclusive, i.e.

$$
\text { improvement rate, } \delta(x, t)=1-\mathrm{m}(\mathrm{x}, \mathrm{t}) / \mathrm{m}(\mathrm{x}, \mathrm{t}-1)
$$

Each improvement rate was then assigned to one central year of birth. For example, the improvement rate for the 60-64 age group, for calendar year 2003, was assigned to year of birth 1941.

Various models can be constructed to decompose the rates of improvement for different causes using a combination of age, period and cohort factors. Age-periodcohort models have been widely used by epidemiologists and demographers to model mortality rates (see, for example, Tabeau 2001). These models are commonly fitted to $\log$ mortality rates. However, for this purpose, the rates of improvement themselves (i.e. the $\delta(x, t)$ terms) have been modelled. This approach is felt to produce results which are relatively easy to interpret and adapt for the projection of future mortality rates.

One feature of age-period-cohort models is that they do not provide a unique solution because of the interdependence of the three terms. There are various strategies to overcome this "identification problem". However, for this particular paper, it was decided to consider the results of a simplified version of the model only, i.e. one with just period and cohort terms:-

$$
\delta(\mathrm{x}, \mathrm{t})=\beta(\mathrm{t})+\gamma(\mathrm{t}-\mathrm{x})
$$

where $\mathrm{t}=$ calendar year, $\mathrm{t}-\mathrm{x}=$ year of birth, $\Sigma \mathrm{w} \gamma(\mathrm{t}-\mathrm{x})=0, \mathrm{w}=\mathrm{a}$ weighting factor for each cohort taken as the number of deaths observed for that cohort. 
This approach can be justified because the model fits rates of improvement rather than log mortality rates.

The missing age term is of far less significance than would be the case with a traditional age-period-cohort model. In fact, this age term can be seen as equivalent, in very broad terms, to the $\mathrm{b}(\mathrm{x})$ term in the Lee-Carter model (Lee and Carter 1992), where:

$$
\log \mathrm{m}(\mathrm{x}, \mathrm{t})=\mathrm{a}(\mathrm{x})+\mathrm{b}(\mathrm{x}) \mathrm{k}(\mathrm{t})
$$

Most significantly there is not a clear pattern to the model residuals by age and time, which would indicate a poor fit.

The model can be fitted using a weighted least squares approach applied directly to actual and expected improvement rates or by using a maximum likelihood or minimum chi-squared function derived for the underlying mortality rates. All three approaches give similar results. In this instance results derived by applying the maximum likelihood approach have been used.

The two functions (i.e. period and cohort) derived from fitting the simplified model to cause-specific mortality data for females are given in Figs. 20.6a, 20.6b, 20.6c, 20.6d, 20.6e, and 20.6f. In each case rolling averages were used to identify underlying patterns in the data. In the case of the period function, the improvement rates for 1984 and 1993 were removed from the analysis as they were distorted by changes in the methodology used to assign a main cause to a death certificate. Likewise the rates for 2001 were also removed because ICD10 was first applied as a method of cause classification in this year.

It is interesting to note that the pattern of the cohort function is very different for lung cancer and heart disease. There is clear evidence that the cohort effect applies to later-born generations in the case of heart disease. This does not correlate well with trends in lung cancer or cigarette consumption by generation.

Another way of exploring how year of birth factors have influenced trends in different causes of death is to analyse how well a basic Lee-Carter model fits mortality rates for different birth years. This approach is illustrated by Fig. 20.7 in which fitted and actual rates are compared. For the three causes of death analysed the Lee-Carter model systematically over-estimated mortality rates for those born in 1935-1945, consistent with the impact of the cohort effect. However, it was again evident that this over-estimation applied to a significantly earlier generation in the case of lung cancer than for the other causes.

It is worth considering some of the characteristics of the causes of death in relation to cigarette smoking.

A review paper by Lee (2000) concluded that the relative lung cancer risk among current smokers was 10-20 times that of those who have never smoked. Furthermore, it was found that it generally took ex-smokers 20-25 years after giving-up to reduce the additional risk by $75 \%$.

On the other hand, a similar review paper on heart disease risk (Lee 2001) concluded that the average relative risk of current smokers to those who have never smoked was $212 \%$. Furthermore, it took ex-smokers 5-9 years after quitting to reduce this additional risk by $75 \%$. 


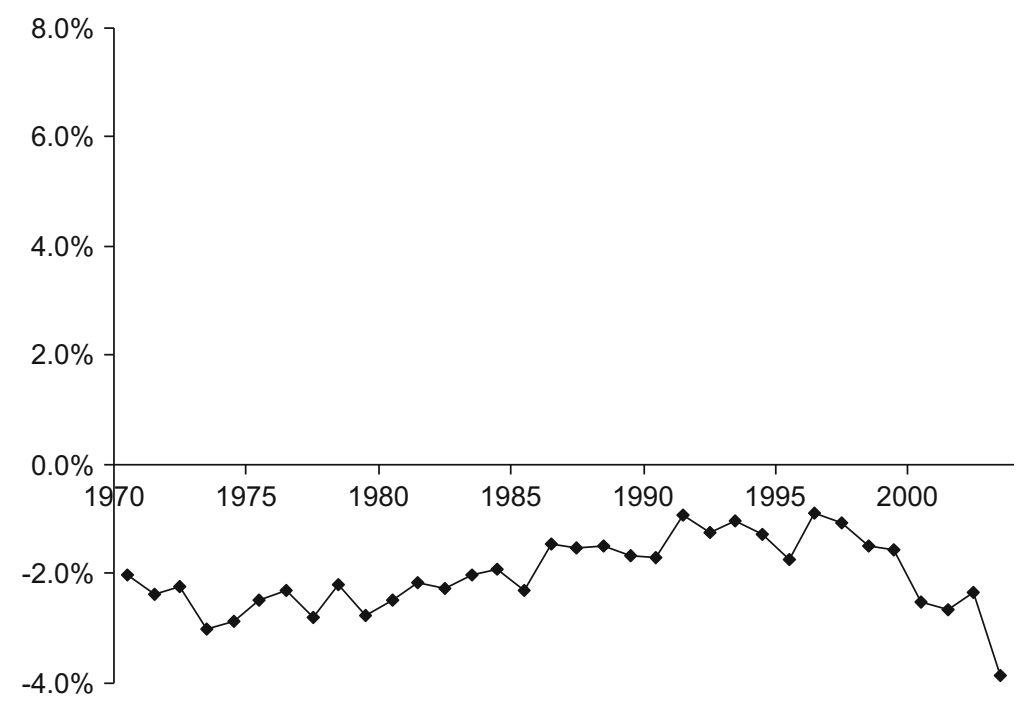

Fig. 20.6a Period function $\boldsymbol{\beta}(\mathrm{t})$ derived by fitting a model of mortality improvement to lung cancer rates for females, England \& Wales, 1968-2003

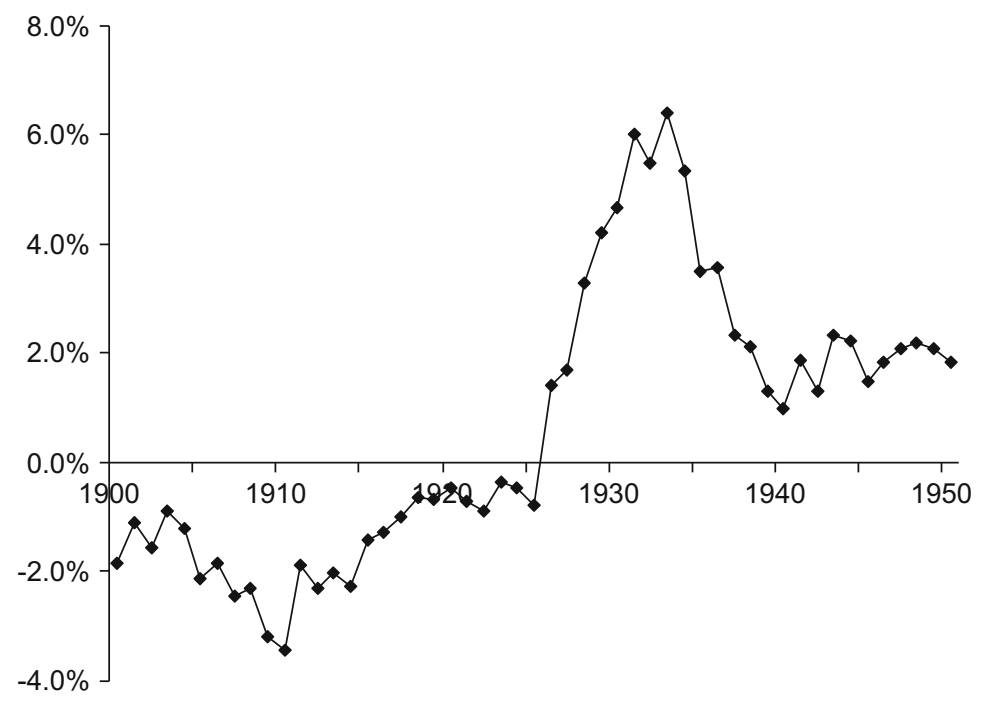

Fig. 20.6b Cohort function $\boldsymbol{\gamma}(\mathrm{t}-\mathrm{x})$ derived by fitting a model of mortality improvement to lung cancer rates for females, England \& Wales, 1968-2003

Thus, it can be argued, historic patterns of smoking are much more likely to cause cohort effects in lung cancer than heart disease mortality.

There is also evidence that breast cancer mortality improvements have been faster for those born after 1925 than for those born before date. This pattern is unlikely to 


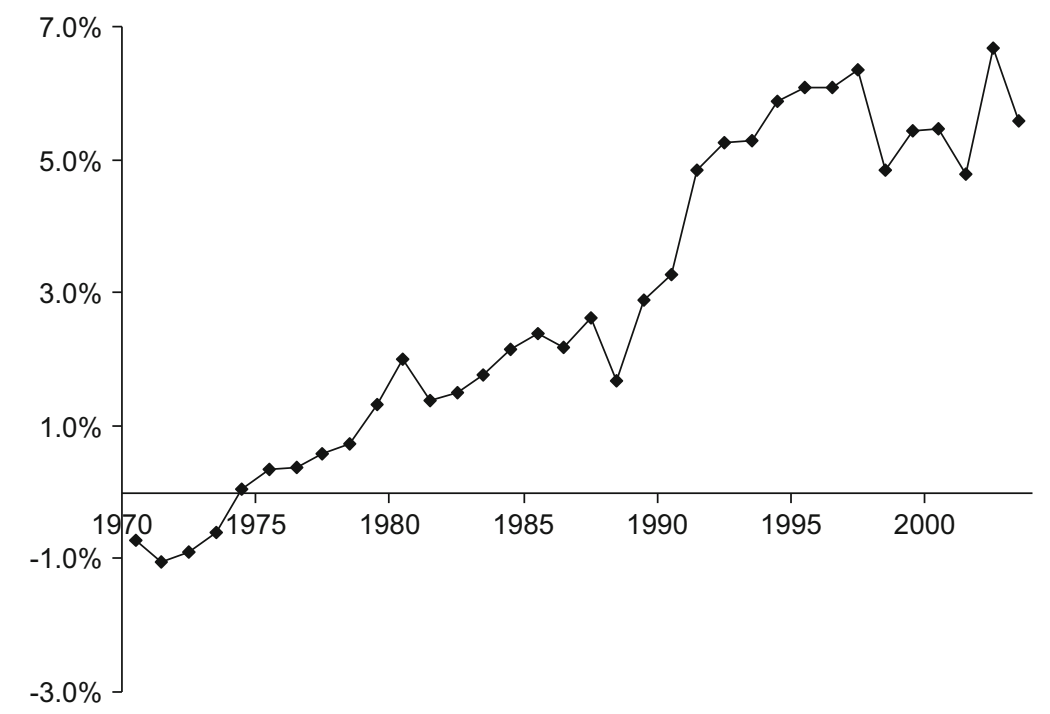

Fig. 20.6c Period function $\boldsymbol{\beta}(\mathrm{t})$ derived by fitting a model of mortality improvement to heart disease rates for females, England \& Wales, 1968-2003

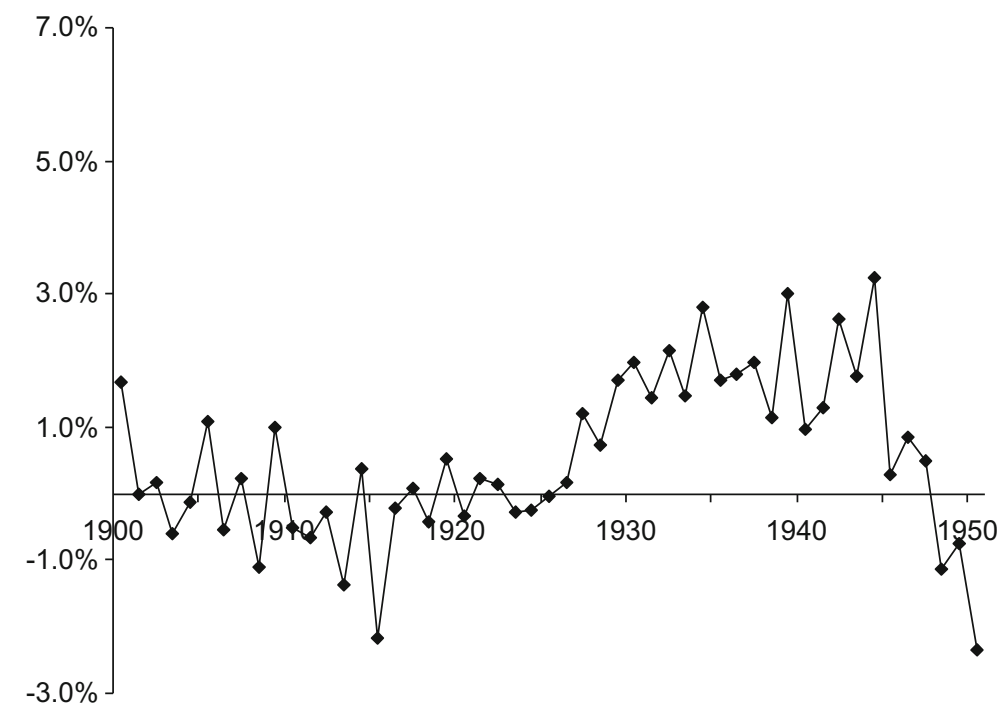

Fig. 20.6d Cohort function $\boldsymbol{\gamma}(\mathrm{t}-\mathrm{x})$ derived by fitting a model of mortality improvement to heart disease rates for females, England \& Wales, 1968-2003

be due to changing patterns of smoking behaviour as smoking is not considered to be a major risk factor in breast cancer. A review paper by McPherson et al. (2000) made the statement that "smoking is of no importance in the aetiology of breast cancer". 


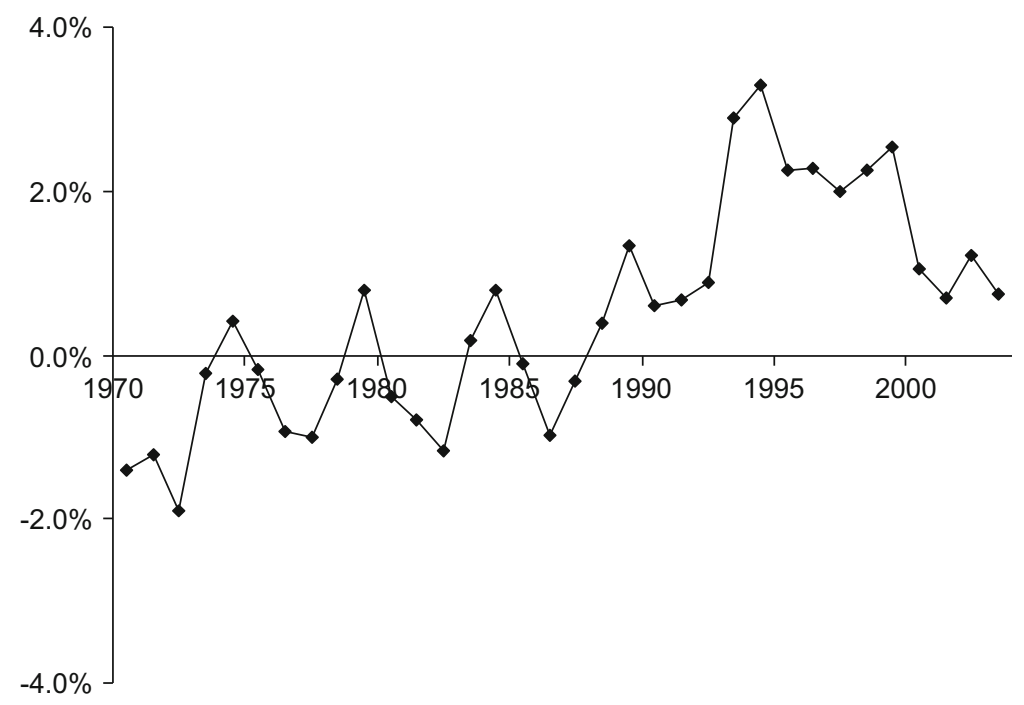

Fig. 20.6e Period function $\boldsymbol{\beta}(\mathrm{t})$ derived by fitting a model of mortality improvement to breast cancer rates for females, England \& Wales, 1968-2003

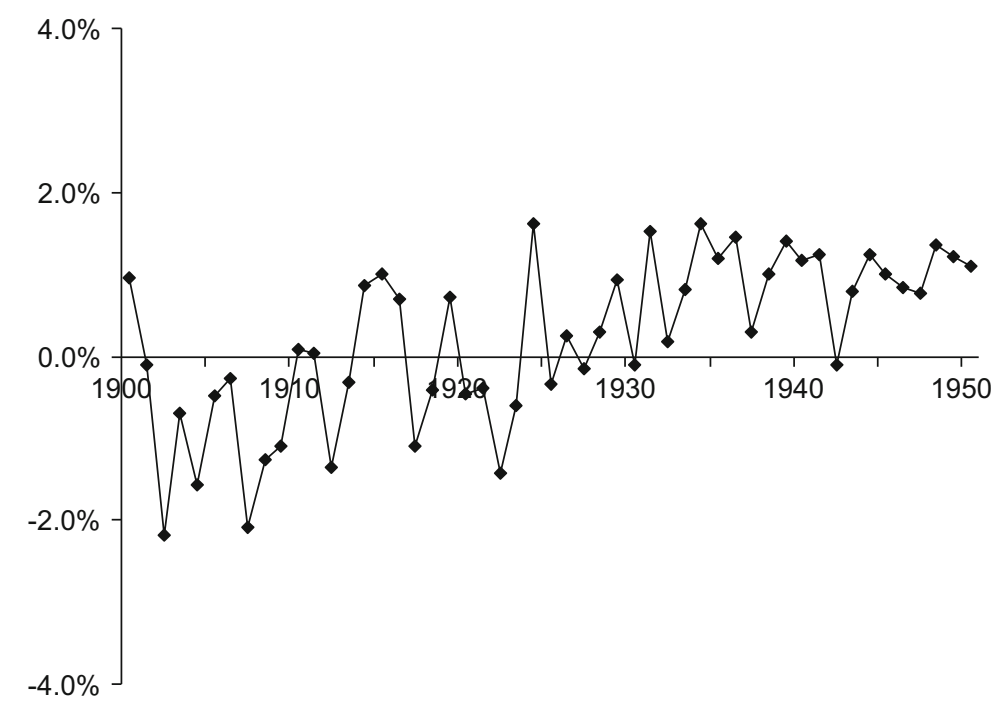

Fig. 20.6f Cohort function $\gamma(\mathrm{t}-\mathrm{x})$ derived by fitting a model of mortality improvement to breast cancer rates for females, England \& Wales, 1968-2003

The observed cohort effect may be partly due to the fact that the NHS Screening Programme for breast cancer was initiated in 1988. This was aimed - initially - at women aged 50-65, so would have most benefited those born in the 1930s and 1940s. However, it is notable that improvements in breast cancer mortality were also 


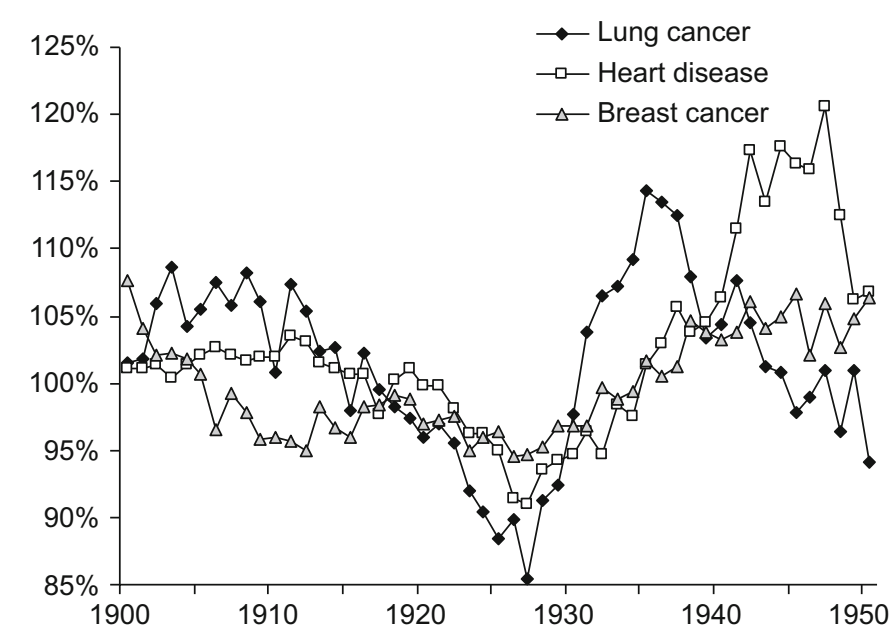

Fig. 20.7 Ratio of "expected" to actual mortality rates derived using a Lee-Carter model fitted to mortality rates for lung cancer, heart disease and breast cancer for females, England \& Wales, 1968-2003, averaged by year of birth

relatively high (compared with other age groups) for women aged in their 30s in the 1970s and in their 40s in the 1980s.

It can therefore be argued that prevalence of cigarette smoking from one generation to the next has certainly been one factor which has driven the UK cohort effect and that, as a result, there is a degree of inevitability in some element of likely future improvement, especially for mortality at older ages from conditions strongly linked to smoking.

However, trends in heart disease and breast cancer mortality suggest that smoking may not be the only factor. In Willets (2004) it is argued that there appear to be two 'sub-cohorts' of the 1925-45 cohort: an earlier group where the improvements are largely due to smoking and a later one where other factors, such as diet in early life or exposure to infectious diseases, may have played a greater role.

The key point for this paper is that analysis of mortality trends by cause of death can play a vital part in determining the factors driving mortality trends, such as the cohort effect. Furthermore it is argued that such an understanding allows trends to be appropriately allowed for in the projection of future mortality rates.

\subsection{Implications and Conclusions}

In section four it was argued that in order to understand trends and observed features in aggregate mortality, trends in individual causes of death need to be analysed.

This understanding is necessary because subjective judgments are always made when projecting future rates of mortality, no matter what method is selected. Even the most mechanical method applied to aggregate mortality rates requires decisions 
to be taken. Specifically, the precise structure of the model needs to be decided and the period of past data on which to base the future projection needs to be chosen.

In projecting future mortality rates for UK pensioners, it is necessary to form a view on (at least) the following points in deriving a suitable methodology:

- Should the model by parameterised using year of birth or attained age components (or both)?

- If year of birth parameters are used, should their effect reduce with time, increasing age or neither?

- Should the general pace of improvement continue at its current pace or be assumed to accelerate or decelerate over time? Should it revert to a long-term average rate and, if so, what time period should be used to calculate that average?

- Should the pace of improvement for males and females converge over time? If so, how long should the period of convergence last?

- Should the pace of improvement be assumed to be faster for (for example, higher socio-economic class) pensioners than for the average population? If so, how much faster and at which ages?

An understanding of the forces driving historic trends is an essential element of making decisions of this nature.

In fact, despite the historical experience of using cause-of-death projections and the well-documented difficulties, there nevertheless appears to be a good argument for utilising cause-of-death projections in making forecasts.

In forecasting mortality rates for those under the age of (say) 80 it can be instructive to divide deaths into a small number of cause-groupings, perhaps those with very strong historic trends, and compare the results with equivalent aggregate projections.

Cause-of-death modelling can also be a good methodology to test "extreme scenarios", which are becoming of increasing interest to insurance regulators and capital markets. Such an approach tends to be welcomed by users of such projections, who can see the methodology "grounded in reality." It can also provide a suitable mechanism for allowing for expert medical opinion in different diseases.

\section{References}

Caselli, G. (1996). Future longevity among the elderly. In G. Caselli \& A. D. Lopez (Eds.), Health and mortality among elderly populations. Oxford: Clarendon Press.

Continuous Mortality Investigation. (1999). CMI Report 17. London: CMI.

Continuous Mortality Investigation. (2002). An interim basis for adjusting the '92 series' mortality projections for cohort effects (Working Paper No. 1). London: CMI.

Continuous Mortality Investigation. (2004). Projecting future mortality: A discussion paper (Working Paper No. 3). London: CMI.

Continuous Mortality Investigation. (2005). Projecting future mortality: Towards a proposal for a stochastic methodology (Working Paper No. 15). London: CMI.

Government Actuary's Department. (2001). National population projections: Review of the methodology for projecting mortality. London: GAD. 
Government Actuary's Department. (2003). '2002-based' UK population projections. London: GAD.

Human Mortality Database., University of California, Berkeley (USA), and Max Planck Institute for Demographic Research (Germany). Available at http://www.mortality.org or http://www. humanmortality.de. (data downloaded on 26 May 2005).

Kelly, M. P., \& Capewell, S. (2004). Relative contributions of changes in risk factors and treatment to the reduction in coronary heart disease mortality (Health Development Agency Briefing Paper). London.

Lee P. N. (2000). A review of the epidemiology of lung cancer related to active smoking. See http:// www.pnlee.co.uk

Lee P. N. (2001). A review of the epidemiology of heart disease related to active smoking. See http://www.pnlee.co.uk

Lee, R. D., \& Carter, L. (1992). Modelling and forecasting US mortality. Journal of the American Statistical Association, 87(419), 659-671.

Lee, P. N., Fry, J. S., \& Forey, B. A. (1990). Trends in lung cancer, chronic obstructive lung disease and emphysema death rates for England \& Wales, 1941-85, and their relation to trends in cigarette smoking. Thorax, 45, 657-665.

McPherson, K., Steel, C. M., \& Dixon, J. M. (2000). Breast cancer - Epidemiology, risk factors and genetics. British Medical Journal, 321, 624-628.

Office for National Statistics. (1997). The health of adult Britain 1841-1994. London: HMSO.

Office for National Statistics. (2004). Living in Britain; Results from the General Household Survey. London: HMSO.

Tabeau, E. (2001). A review of demographic forecasting models for mortality. In E. Tabeau, A. van den Berg Jeths, \& C. Heathcote (Eds.), Forecasting mortality in developed countries: Insights from a statistical, demographic and epidemiological perspective (European studies of population) (Vol. 9). Dordrecht: Kluwer Academic Publishers.

UK Actuarial Profession. (2004). Individual capital assessment. Version 1.1. Guidance Note 46.

Unal, B., Critchley, J. A., \& Capewell, S. (2004). Explaining the decline in coronary heart disease mortality in England \& Wales between 1981 and 2000. Circulation, 109, 1101-1107.

Willets, R. C. (2004). The cohort effect: Insights and explanations. British Actuarial Journal, 10(4), 833-877.

Willets, R. C., Gallop, A. P., Leandro, P. A., Lu, J. L. C., Macdonald, A. S., Miller, K. A., Richards, S. J., Robjohns, N., Ryan, J. P., \& Waters, H. R. (2004). Longevity in the 21st century. British Actuarial Journal, 10(4), 685-832.

Wilmoth, J. R. (1997). In search of limits. In K. Wachter \& C. Finch (Eds.), Between Zeus and the Salmon: The biodemography of longevity. Washington, DC: National Academy Press.

Open Access This chapter is licensed under the terms of the Creative Commons Attribution 4.0 International License (http://creativecommons.org/licenses/by/4.0/), which permits use, sharing, adaptation, distribution and reproduction in any medium or format, as long as you give appropriate credit to the original author(s) and the source, provide a link to the Creative Commons license and indicate if changes were made.

The images or other third party material in this chapter are included in the chapter's Creative Commons license, unless indicated otherwise in a credit line to the material. If material is not included in the chapter's Creative Commons license and your intended use is not permitted by statutory regulation or exceeds the permitted use, you will need to obtain permission directly from the copyright holder. 